\section{A OFERTA AMBIENTAL DO GERRADO E SEU USO}

\section{Sueli Matiko Sano}

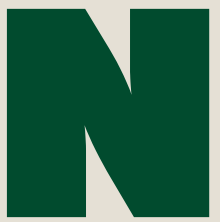

a alta heterogeneidade ambiental do bioma Cerrado diversos seres coexistem no espaço de cerca de 200 milhôes de hectares de extensão. À medida que uma espécie começa a expandir o seu território, outras tendem à extinção se não houver local adequado com alimento, água ou abrigo para os animais se reproduzirem ou água, luz e nutriente para os vegetais. Além de superar as limitaçōes e competir pelo recurso mais escasso, a dominância ou o tamanho da população é em parte resultado do seu poder de agressão. A espécie humana vem ocupando áreas extensas no Cerrado, modificando ambientes para seu usufruto, introduzindo espécies e expulsando outras.

0 AMBIENTE Um mosaico de formações florestais, savânicas e campestres resultantes da interação com clima, solo e relevo, dificultam um consenso sobre o limite e extensão do Cerrado. Essa questão pode ter impacto local forte no uso da terra nas áreas de transição com a Amazônia, devido a diferenças na proporção de reservas legais, a serem alocadas nas propriedades, que têm a função de manter o equilíbrio do ecossistema.

A vegetação expressa o tipo de solo de onde retira os nutrientes, levando-se em consideração a posição topográfica e lençol freático. As formações florestais são visíveis em solos mais férteis ou com disponibilidade de água. Afloramentos rochosos ou solos ricos em ferro e magnésio com cobertura de mata são encontrados entre os solos intemperizados, ácidos, pobres em nutrientes como fósforo, potássio, cálcio, magnésio, contendo alumínio e micronutrientes com formaçôes savânicas de cerrado ou campo. Sob ação de cerca de $1500 \mathrm{~mm}$ de chuva por ano, concentrados em seis meses, os latossolos mantêm os recursos hídricos da bacia do rio São Francisco que percorre uma das regiōes secas do sertão.

As extensas áreas de relevos planos dos planaltos são as áreas que captam água da chuva e abastecem vagarosamente os rios. A água do Cerrado vem com as chuvas que iniciam na primavera e continuam por todo verão até o outono, quando a falta de chuva e baixa umidade relativa do ar anunciam o inverno de temperatura amena; caracterizando-se como clima tropical úmido $(\mathrm{Aw})$. Eventuais períodos curtos sem chuva no verão trazem riscos na produção agrícola, assim como a chuva no meio do inverno quebra a rotina dos viventes, alterando os eventos de emissão das folhas e sua queda, floração e crescimento de frutos. A variação da pluviometria resulta das massas de ar que vêm dos oceanos trazendo umidade para o continente (1). No livro Cerrado: ecologia e flora (2) estão apresentadas as características, descrição das fisionomias e a riqueza de espécies vegetais do Cerrado. No ordenamento territorial no Cerrado (3) verifica-se ações em andamento para criação de reservas extrativistas, uma alternativa para a sobrevivência da sociobiodiversidade e de uso mais sustentável do que a monocultura que se expandiu a partir de 1970 .
A EXPANSÃO AGROPECUÁRIA A mudança da capital brasileira para o centro do país, no coração do Cerrado, deu início ao processo para expansão da fronteira agrícola no Centro-0este. Programas governamentais como o Programa de Desenvolvimento dos Cerrados (Polocentro) criado em 1975, seguidos pelo Programa de Cooperação Nipo-Brasileira para Desenvolvimento dos Cerrados (Prodecer) iniciado em 1979, impulsionaram a exploração agropecuária empresarial com crédito altamente subsidiado (4) voltada para a produção de grãos, principalmente milho, soja e trigo. A execução vem sendo coordenada pela Companhia de Promoção Agrícola (Campo) empresa binacional com participação do governo japonês que promove seleção dos agricultores, assistência técnica às cooperativas participantes e fornecimento de equipamentos de produção aos assentados do Prodecer. A primeira fase foi executada com sucesso em Minas Gerais, mas a segunda iniciada em 1985, com maior área de abrangência no total de 200 mil ha nos estados de Bahia, Goiás, Mato Grosso, Mato Grosso de Sul e Minas Gerais, ainda carrega endividamentos causados pelos altos juros dos financiamentos, e vários planos econômicos governamentais (5).

A alta tecnologia no campo aumentou a oferta de mão-de-obra na cidade e mercado consumidor. A implantação de infraestrutura e a instalação de unidades agroindustriais próximas às áreas produtoras como os complexos de carne de frango e suíno, e da soja na região goiana de Rio Verde, mudou o cenário do Centro-Oeste. O lado positivo desse processo foi a geração de emprego para a população urbana, pois induziu a instalação de indústrias de insumos, máquinas, embalagens e o setor de serviços. Além disso, aumentou a produção de feijão, café, algodão, arroz, frutas e olerícolas para abastecer as cidades.

A mudança da paisagem natural do centro brasileiro teve contribuição do Centro de Pesquisa Agropecuária dos Cerrados (CPAC), unidade da Empresa Brasileira de Pesquisa Agropecuária (Embrapa), vinculado ao Ministério da Agricultura, Pecuária e Abastecimento. Foi criado em 1975 com o objetivo de realizar pesquisa sobre o Cerrado, enfocando três temas principais: avaliação dos recursos naturais (solo, clima e vegetação), superação dos fatores limitantes para a atividade agrícola (acidez e baixa fertilidade do solo, deficiência hídrica) e desenvolvimento de sistemas agropecuários (pecuária, produção de grãos e fruticultura). Os intercâmbios entre pesquisadores de instituiçóes de pesquisa e universidades nacionais e internacionais subsidiaram o avanço dos conhecimentos e tecnologias, adotados de imediato pelos agricultores organizados, o quetransformou o Cerrado em um grande celeiro, em poucas décadas.

Algumas das principais tecnologias (6) são: uso da calagem para reduzir a acidez do solo, fertilizantes para produção de grãos, gessagem para carrear nutrientes em profundidade favorecendo o crescimento de raízes e aumentando a resistência à deficiência hídrica, assim como a inoculação de rizóbio que fixa o nitrogênio atmosférico dispensando a adubação química nitrogenada na produção de soja. Esta última é uma vantagem competitiva na produção de grãos devido à economia na aquisição de adubo, e pode ser sucedido por outra safra de ciclo curto.

A produção de grãos e a bovinocultura ocupam a maior área do 
Cerrado transformada pela espécie humana. A produção de grãos é baseada no uso de insumos, fertilizantes, herbicidas e fungicidas aplicados nos planaltos e que são exportados na forma de soja, farelo de soja e milho. Para alimentar o gado bovino, capins de origem africana têm ocupado vastos espaços cerradenses. Mais recentemente a renovação de pastagens com a produção de grãos tem aumentado a produtividade e o ganho dos agricultores, aumentando a eficiência do uso das áreas já ocupadas.

$\mathrm{Na}$ medida em que a atividade agropecuária ou silvicultural substitui a paisagem natural, os conhecimentos e a cultura local, junto com os seus povos, são transformados ou esprimidos. Porém, ainda existem os resilientes, aqueles que são capazes de suportar a pressão, superar e se renovar. Dentre as espécies do Cerrado, por exemplo, pequi e cagaita rebrotam nas pastagens mais antigas, áreas onde a aração do solo não é intensa como a de produção de grãos. Nas áreas de ocupação empresarial, a integração lavoura-pecuária e, brevemente, a silvicultura como oportunidade e opção de renda, está cada vez mais definindo o território para a riqueza humana, gerada pela tecnologia. Mas, a cultura e a diversidade são outras riquezas do Cerrado.

REOCUPAÇÃO DOS ESPAÇOS As marcas ambientais da ocupação humana, como a retirada da cobertura vegetal original, alterou a infiltração da água pluvial nos planaltos e o abastecimento dos lençóis freáticos, diminuindo o fluxo de água para os rios. São muitas as nascentes que já secaram nos domínios do Cerrado, como está registrado pelos vários depoimentos de populações (7) que ficaram espremidas pela ocupação de monoculturas densas e extensas de eucalipto no norte mineiro (8). Essa população lutou pelo direito de receber suas terras de volta e, através do Incra, ATER, em conjunto com o Ministério do Meio Ambiente, há expectativa de reativar os meios de vida integrando a atividade humana com o ambiente do Cerrado. Das áreas impróprias para cultivo onde ainda persiste vegetação natural podem-se obter as sementes para a revegetação de áreas desmatadas indevidamente e renovar o uso de produtos do Cerrado. $\mathrm{O}$ uso de plantas na medicina popular (9) e o manejo de algumas espécies frutíferas (10) estão registrados em livros, abrindo oportunidade e espaço para meios de vida mais sustentáveis e para exploração dos conhecimentos locais para conviver com a diversidade. Conhecimentos científicos (11) para diminuir impactos da agricultura sobre o ciclo hidrológico, tornar efetiva a participação do Cerrado em área de redução da emissão de gases de efeito estufa com plantio de espécies arbóreas são algumas das açōes imediatas para melhorar a qualidade de vida. A transformação das áreas de uso alternativo em ambientes saudáveis é um desafio não só do governo, mas da consciência e educação da população.

Sueli Matiko Sano é bióloga, doutora em ecologia, pesquisadora da Embrapa Cerrados na área de recursos naturais.

\section{REFERÊNCIAS BIBLIOGRÁFICAS}

1. Silva, F. A. M. da; Assad, E. D.; Evangelista, B. A. "Caracterização climática do bioma Cerrado". In: Cerrado: ecologia e flora. Brasília: Embrapa, pp 71-88. 2008.

2. Sano, S. M.; Almeida, S. P. de; Ribeiro, J. F. (Ed.). Cerrado: ecologia e flora. Brasília: Embrapa Informação Tecnológica:Planaltina: Embrapa Cerrados, 2008

3. Silva, C.E.M. Desenvolvimento e meio ambiente, 19, p.89-109. 2009.

4. Muller, C.C. "Políticas governamentais e expansão recente da agropecuária no Centro-Oeste". In: Planejamento e políticas públicas. Brasília: IPEA, 3, pp 45-74. 1990.

5. Mizumoto, C. N.; Cruz, J. C. A. S. da; Ogura, Y. Prodecer. In: O Cerrado e o seu brilho. São Paulo: Caramuru, p.138-213. 2009.

6. Sousa, D. M. G. de; Lobato, E. (Ed.).Cerrado: correção do solo e adubação. Planaltina: Embrapa Cerrados, 416 p. 2004.

7. Silva, C.E.M. "Desenvolvimento e sustentabilidade no Cerrado: o caso do sertão norte-mineiro". In: Cerrado e desenvolvimento: tradição e atualidade. Montes Claros: Centro de Agricultura Alternativa do Norte de Minas; [Goiânia]: Rede Cerrado de Organizações Não Governamentais, p.273-309.2000.

8. Ribeiro, E.M. Histórias dos gerais. Belo Horizonte: UFMG, 329p. 2010.

9. Articulação Pacari. Farmacopéia popular do Cerrado. Goiás. 347p. 2009.

10. Bensusan, N. Unindo sonhos: pesquisas ecossociais no Cerrado. Brasília: Instituto Internacional de Educação do Brasil. 328p. 2009.

11. Parron et al. Cerrado: desafios e oportunidades para o desenvolvimento sustentável. Planaltina: Embrapa Cerrados. 464p. 2008. 